\title{
Interpretation of Pin-1 and VEGF-C expression in breast infiltrating duct carcinoma
}

\author{
BYUNG-CHUL KIM ${ }^{1}$ SONG-IY HAN ${ }^{2}$ and SUNG-CHUL LIM ${ }^{1,2}$ \\ ${ }^{1}$ Department of Pathology and ${ }^{2}$ Research Center for Resistant Cells, \\ Chosun University School of Medicine, Gwangju, Korea
}

Received June 3, 2009; Accepted August 28, 2009

DOI: 10.3892/or_00000578

\begin{abstract}
Pin-1 has been shown to regulate several phases of the cell cycle and is strikingly overexpressed in many human cancers. Vascular endothelial growth factor (VEGF)-C is a potent lymphangiogenic factor produced by tumor and stromal cells. However, little is known about the roles of Pin-1 and VEGF-C in breast carcinoma. p53 protein and cyclin D1 overexpressions have been shown to play a role as prognostic factors in many human cancers. To better understand the roles of Pin-1 and VEGF-C in breast carcinoma, we evaluated the immunohistochemical expression of Pin-1 and VEGF-C in relationship with p53 protein or cyclin D1 overexpression and clinicopathological parameters in 128 mammary infiltrating duct carcinomas. There was a positive expression in $100 \%$ of Pin-1, 88\% of VEGF-C, 35\% of p53 protein, and $66 \%$ of cyclin D1 in the breast carcinoma. Correlation of the positive expression of Pin-1 with tumor grade $(\mathrm{p}<0.01)$ and lymph node metastasis or cyclin D1 overexpression ( $\mathrm{p}<0.05$, respectively) was statistically significant. Significant correlation was observed between VEGF-C and tumor grade, lymph node metastasis or clinical stage $(\mathrm{p}<0.01$, respectively). These results indicate that elevated Pin-1 or VEGF-C expression is more common in infiltrating duct carcinomas with poor prognostic characteristics and is partly associated with an unfavorable outcome. Given the role of cyclin D1 overexpression in oncogenesis of breast, these results suggest that overexpression of Pin-1 and VEGF-C may promote tumor progression and metastasis.
\end{abstract}

\section{Introduction}

Recently characterized peptidyl-prolyl cis/trans isomerase (PPIase) Pin-1 is involved in the control of cell cycle by phosphorylation through the epidermal growth factor, migrating

Correspondence to: Dr Sung-Chul Lim, Department of Pathology Chosun University Hospital 588, Seosuk-dong, Dong-gu, Gwangju, Korea

E-mail: sclim@chosun.ac.kr

Key words: Pin-1, VEGF-C, p53 protein, cyclin D1, breast, carcinoma, prognosis from the nucleus to the cytoplasm, and inducing cell death. However, as Pin-1 has been revealed to be involved in oncogenesis in various organs, attention has been paid to its accurate action mechanism. Pin-1 accelerates the cis/trans isomerization of specific proteins, and consequent structural changes may exert a great effect on numerous Pin-1 substrates (1-4). Among them, the important oncogenic proteins ß-catenin and cyclin D1 have been characterized to be controlled by Pin- 1 in such a manner $(5,6)$. The overexpression of Pin-1 has been reported to be associated with the development of various cancers, and proportional to tumor grades. Pin-1 binds to phosphorylated c-Jun and increases cyclin D1 mRNA and protein in cells, whereas the suppression of endogenous Pin-1 decreases the transcriptional activity of phosphorylated c-Jun (6).

Lymphatic ducts are important in the metastasis of cancer, and lymph node metastasis is the most important prognostic factor determining the poor prognosis of various cancers. Among numerous studies on cancer metastasis, studies on lymphangiogenesis are ongoing actively, which is due to the discovery of the important lymphatic duct growth factors VEGF-C and -D, nonetheless, their precise role has not been characterized yet $(7,8)$. VEGF-C, a member of the VEGF family, is a ligand of VEGF receptor-3 (VEGFR-3, Flt4) that is known to be a specific marker of lymphatic endothelial cells and induces the proliferation of lymphatic ducts $(9,10)$. VEGF-C has been known to not only control physiological angiogenesis and the development as well as progression of diverse angiogenic diseases but also to accelerate tumor lymhangiogenesis, and thus to induce dissemination of cancer cells and lymph node metastasis $(11,12)$.

In Korea, the incidence of breast cancer is on the rise, it is the leading cancer among females despite the improvement of diagnosis and therapeutic methods, it is the leading cause of the cancer mortarlity in women (13). Among factors influencing the prognosis of breast cancer, tumor size and the presence or absence of lymph node metastasis have been reported to be the most important independent prognostic factors $(14,15)$, and as supplement prognostic factors that allow to distinguish the high risk group with recurrence potential. Studies on the role of DNA ploidy, proliferation index (16), various receptors $(17,18)$, oncogenes such as Her-2/neu and p53 protein, and tumor suppressor genes $(19,20)$ have been conducted. 
Pin-1 and VEGF-C are known to play an important role in the formation, progression and metastasis of various tumors, nonetheless, such reports in breast cancer are scarce. Therefore, in infiltrating duct carcinoma patients, by immunohistochemical staining, we compared and analyzed based on several clinicopathological data including clinical stage, the survival length of patients, the age of patients, tumor size, histological grade, the number of lymph node metastasis, and examined the relationship of cyclin D1 with p53 protein. In addition, their effect on the progression of tumor and the prognosis of patient were statistically analyzed.

\section{Materials and methods}

Patients. Among the women who underwent mastectomy for infiltrating duct carcinoma at Chosun University Hospital (Gwangju, Korea) from January 1990 to June 1996, the present study was done in 128 patients whose paraffin embedded tissues were relatively well preserved. Informed consent was obtained from all patients, and research protocols were approved by the Ethics Committee of Chosun University Hospital. The relationship with survival was investigated in 123 patients, for 5 patients the follow-up was not possible. Patients who underwent chemotherapy or radio-therapy were excluded from the study. Patient age, tumor size, number of lymph node metastasis, and clinical stage were confirmed by reviewing patient charts and pathology files. Patient survival was confirmed through phone calls and mail. The range of follow-up after the first diagnosis was between 1-116 months (less than 40 months, 22 cases; 40-59 months, 52 cases; 60-79 months, 24 cases; 80-99 months, 24 cases; longer than 99 months, 6 cases).

Histological assessment. Histological grade of tumor cells used for the study was the modified version of Bloom-Richardson grading system used in the Nottingham/Tenovus Breast Cancer Study (21). Tumor size was divided into those $<2 \mathrm{~cm}$ (T1), between $2-5 \mathrm{~cm}$ (T2), and $>5 \mathrm{~cm}$ (T3) according to the TNM classification of the American Joint Committee on Cancer (22). Metastasis to axillary lymph node was divided into no metastasis (N0), 1-3 lymph node metastasis (N1), and 4 or more than 4 lymph node metastasis (N2) according to the criteria by Fisher et al (23). Clinical stage was divided according to the staging system set by the American Joint Committee on Cancer Staging (22).

Immunohistochemical staining. All tumors investigated in the study were tested for Pin-1 rabbit polyclonal antibody (Santa Cruz Biotechnology, Santa Cruz, CA, USA; dilution 1:400), VEGF-C goat polyclonal antibody (N-19, Santa Cruz Biotechnology; dilution 1:50), p53 mouse monoclonal antibody (DO-7, Dako, Glostrup, Denmark; dilution 1:200) and cyclin D1 rabbit polyclonal antibody (H-295, Santa Cruz Biotechnology; dilution 1:100). Immunolocalization for Pin-1, p53 protein and cyclin D1 was performed using a HistostainPlus kits, broad spectrum (Zymed, San Franscisco, CA, USA) and immunolocalization for VEGF-C was performed using a goat ImmunoCruz ${ }^{\mathrm{TM}}$ staining system (Santa Cruz Biotechnology), according to the supplier's protocol. Briefly,
4- $\mu \mathrm{m}$ thick sections obtained after formalin fixation and paraffin embedding were deparaffinized in xylene and rehydrated with distilled water through graded concentrations of ethanol. Then the sections were placed in a glass jar with $10 \mathrm{mM}$ citrate buffer $(\mathrm{pH} 6.0)$ and irradiated in a microwave oven for $15 \mathrm{~min}$, and cooled down in the jar at room temperature for $20 \mathrm{~min}$. Then, the slides were rinsed with Tris-buffered saline (TBS). After quenching the endogenous peroxidase activity in $0.3 \%$ hydrogen peroxide for $10 \mathrm{~min}$, blocking reagent was added for $10 \mathrm{~min}$. The slides were then washed as before, and were subsequently subjected to the primary antibody reaction. Each primary antibody for Pin-1 and p53 protein was applied $1 \mathrm{~h}$ in a moist chamber at $37^{\circ} \mathrm{C}$. VEGF-C and cyclin D1 was applied in a moist chamber overnight at $4^{\circ} \mathrm{C}$. After washing with TBS, the biotinylated link antibody was applied for $10 \mathrm{~min}$, followed by horseradish peroxidase (HRP) bound streptavidin for an additional $10 \mathrm{~min}$. After washing with TBS, the localization of anti-bodies was visualized by incubating the sections for $15 \mathrm{~min}$ in HRP substrate and counterstaining with Mayer's hematoxylin. An isotype matched control antibody was also used. Positive control for VEGF-C was early placenta tissue, those for PIN-1 and p53 were colonic adenocarcinoma with strong nuclear staining in another study, and that for cyclin D1 was mantle cell lymphoma. Instead of the primary antibody, normal goat serum was used in negative control.

Analysis and interpretation of staining. In the staining for Pin-1, cases showing reaction within the nucleus was considered to be positive reaction, and depending on the reaction intensity, they were classified as strongly positive $(3+)$, moderately positive $(2+)$, weakly positive $(1+)$, and negative ( 0 , no staining) (24).

In the staining for VEGF-C, cases showing staining reaction within the cytoplasm was determined to be positive reaction, and the entire tumor cells were evaluated based on the specimen performed immunostaining, and cases without staining was determined to be negative (-), cases showing positive cells focally in $<5 \%$ of tumor were $1+$, cases positive in $5-20 \%$ were $2+$, and cases positive in $>20 \%$ were $3+$, and $2+$ and $3+$ were re-classified as the high expression group and $1+$ as the low expression group (8).

Staining for cyclin D1 and p53 was determined positive when nuclear protein was stained red brown under optical microscope, was negative when nuclear staining was present in $<5 \%$ of the area of tumor cells, $1+$ when $5-10 \%$ of tumor cell nuclei was stained positive, $2+$ when $11-50 \%$ was stained positive, and $3+$ when $>50 \%$ was stained positive (25).

Statistical analysis. SPSS (statistical package for the social sciences), Windows version 12 (SPSS, Korea) was used for statistical analysis. $\chi^{2}$ test was used to determine the correlation between clinical stage, patient age, histological tumor grade, tumor size, and lymph node metastasis and expression patterns of Pin-1, VEGF-C, p53 and cyclin D1; correlation in the expression patterns among Pin-1, VEGF-C, p53 and cyclin $\mathrm{D} 1$; and correlation between the expression patterns of Pin-1, VEGF-C, p53 and cyclin D1 and survival. Wilcoxon rank 


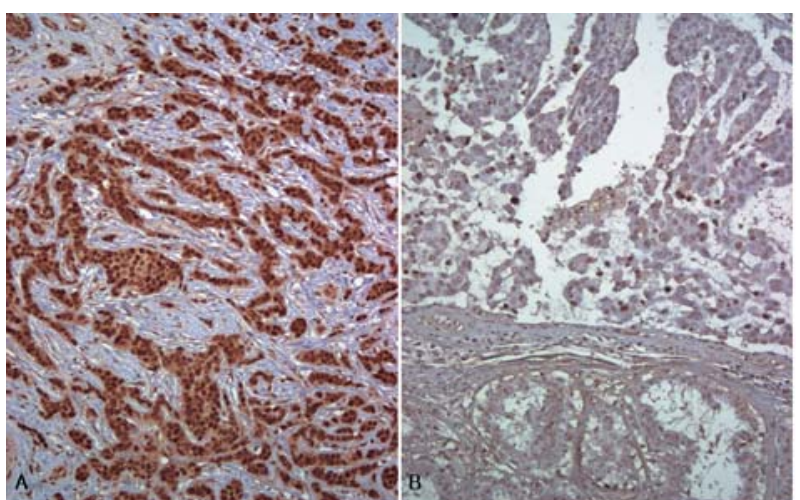

Figure 1. Immunohistochemical staining for Pin-1 in mammary infiltrating duct carcinoma. High grade carcinoma demonstrated strong positive nuclear staining (A) but, lower grade carcinoma demonstrated weak positive nuclear staining (B).

test was used for the analysis of Kaplan-Meier survival. Statistical significance was determined at $\mathrm{p}<0.05$.

\section{Results}

Clinical data. The range of patient age was 25-79 years (average: 49 years). Age distribution according to each age group showed that 24 patients $(19 \%)$ were under 40 years of age, $46(36 \%)$ were between $40-49$ years of age, $37(29 \%)$ were between $50-59$, and $21(16 \%)$ were 60 or older than 60 years of age. The range of tumor size was between $0.5-8.5 \mathrm{~cm}$ (average: $2.7 \mathrm{~cm}$ ) in which 56 patients $(44 \%)$ showed tumors $<2 \mathrm{~cm}, 62(48 \%)$ had tumors between 2.0 and $5.0 \mathrm{~cm}$, and 10 $(8 \%)$ had tumors $>5.0 \mathrm{~cm}$.

Histological assessment. When tumors were divided according to the histological grading system used in the Nottingham/ Tenovus Breast Cancer Study, 31 cases (24\%) were grade 1, $61(48 \%)$ were grade 2 , and $36(28 \%)$ were grade 3 . Lymph node metastasis was not present in 71 cases $(56 \%)$, lymph node metastasis to 1-3 nodes was observed in 23 (18\%), and to 4 or $>4$ nodes in $34(27 \%)$. Clinical stage of tumor was stage 1 in 34 cases (27\%), stage 2 in $77(60 \%)$, and stage 3 in $17(13 \%)$.

Immunohistochemical expression patterns of Pin-1, VEGF-C, p53 protein and cyclin D1. The weak staining (1+) of Pin-1 was detected even in the nucleus of normal breast tissues in the vicinity of tumor. In infiltrative lymphatic cancer cases, in most cases, moderately or strongly positive $(2+$ or $3+)$ staining was observed, and in cases with ductal carcinoma in situ (DCIS) in the vicinity, weak positive results (1+) were shown in most cases. In infiltrating duct carcinoma cases, among 128 cases of study subjects, none showed negative results, 14 cases were weak positive, 32 cases were moderately positive, and 82 cases (64\%) showed strongly positive results (Fig. 1).

VEGF-C was observed in the cytoplasm of tumor cells, but it was not detected in normal breast tissues. Among 128 study sujects, 16 cases were negative, and 112 cases $(87.5 \%)$ were positive, and among them, the distribution that 34 cases

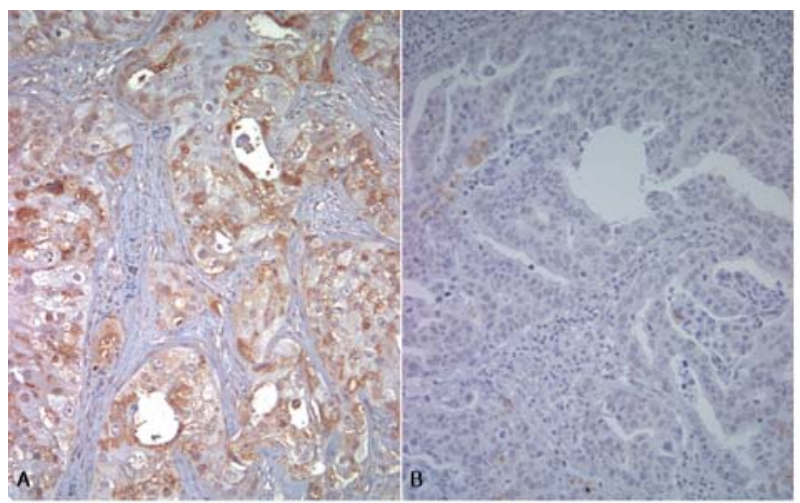

Figure 2. Immunohistochemical staining for VEGF in mammary infiltrating duct carcinoma. High grade carcinoma demonstrated strong positive cytoplasmic staining (A) but, lower grade carcinoma demonstrated weak positive cytoplasmic staining (B).

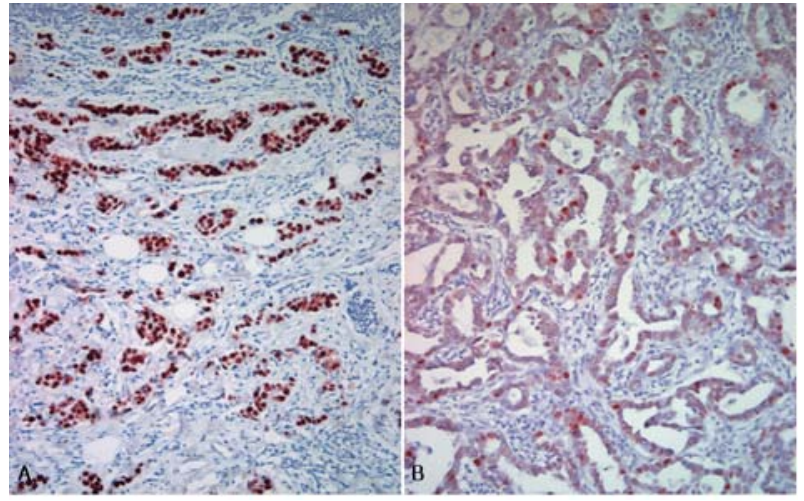

Figure 3. Immunohistochemical staining for p53 protein in mammary infiltrating duct carcinoma. High grade carcinoma demonstrated strong positive nuclear staining (A) but, lower grade carcinoma demonstrated weak positive nuclear staining (B).

were $1+, 50$ cases were $2+, 28$ cases were $3+$ (strongly positive group, 78 cases; weakly positive group, 34 cases) was shown. In regard to the histological tumor grade distribution of VEGF-C positive cases, grade I was 21 cases (67.7\%), grade II was 55 cases $(90.2 \%)$, and grade III was 36 cases (100\%) (Fig. 2).

Concerning p53 protein, positive results were detected only in the nucleus of tumor cells and not in normal tissues in the vicinity. Among the 128 cases, 45 cases (35.2\%) were shown to be positive, 6 cases were $1+, 13$ cases were $2+$, and 26 cases were shown to be $3+$. Examining the distribution of the histological tumor grade of p53 positive cases, grade I was 2 cases $(6.5 \%)$, grade II was 27 cases $(44.3 \%)$, and grade III was 16 cases $(44.4 \%)$ (Fig. 3 ).

In addition, cyclin D1 was detected only in the nucleus of tumor cells, and it was not observed in normal tissues in the vicinity. Among 128 research subjects, 85 cases (66\%) showed overexpression, and among them, weak overexpression in 28 cases (22\%), moderate overexpression in 22 cases $(17 \%)$, and strong overexpression in 35 cases $(27 \%)$. In regard to the distribution of tumor grade of cases showing cyclin D1 overexpression, grade I was 9 cases (29.0\%), grade 


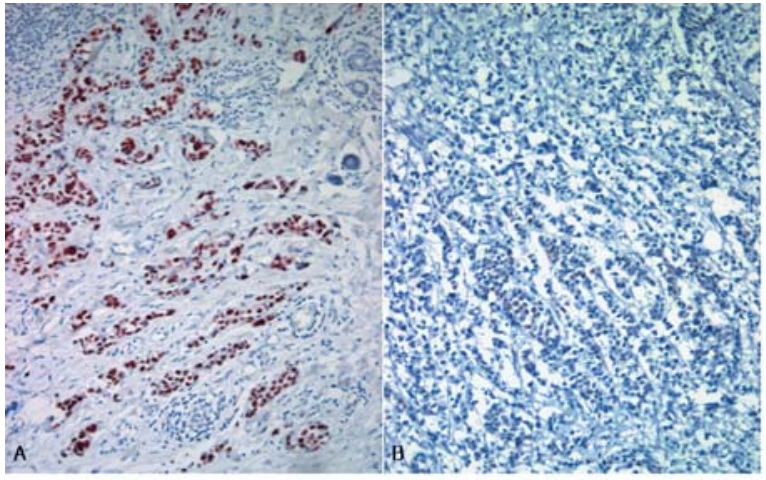

Figure 4. Immunohistochemical staining for cyclin D1 in mammary infiltrating duct carcinoma. High grade carcinoma demonstrated strongly positive nuclear staining (A) but, some high grade carcinoma demonstrated weakly positive nuclear staining (B).

II was 46 cases $(75.4 \%)$, and grade III was 30 cases $(83.3 \%)$ (Fig. 4).

Correlation between Pin-1 expression and clinicopathological parameters. The expression of Pin-1 and histological grade as well as the level of lymph node metastasis were statistically significant $(\mathrm{p}<0.01$ and $\mathrm{p}<0.05$, respectively), nonetheless, it was not significantly associated with the age of patients, tumor size, and clinical stage. In other words, in cases showing the positive expression of Pin-1, particlualry, in cases showing strong positive, the histological grade of tumor was elevated, and the result of the increase of lymph node metastasis was shown (Table I).

Correlation between VEGF-C expression and clinicopathological parameters. The expression of VEGF-C and histological grade, the level of lymph node metastasis and clinical stage $(\mathrm{p}<0.01 \mathrm{each})$ were statistically significant, but it did not significantly correlate to the age of patient and tumor size. In other words, cases showing the positive expression of VEGF-C, particularly cases showing strong positive, the result that the histological grade was increased, lymph node metastasis was increased, and the clinical stage of tumor was increased was shown (Table I).

Correlation between 553 protein expression and clinicopathological parameters. The expression of p53 protein and histological grade were statistically significantly correlated

Table I. The clinicopathological data according to the expression pattern of Pin-1, VEGF-C, p53 and cyclin D1 in mammary infiltrating duct carcinoma.

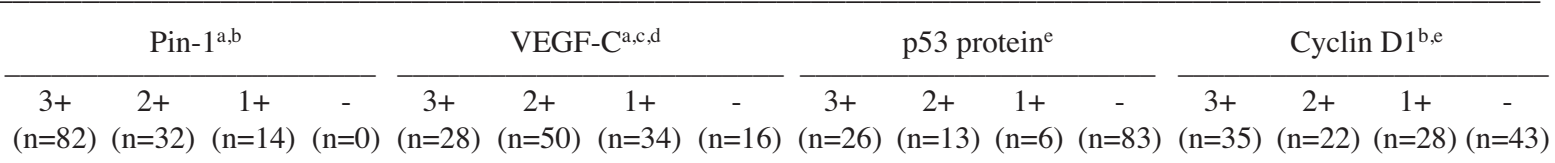

\begin{tabular}{|c|c|c|c|c|c|c|c|c|c|c|c|c|c|c|c|c|}
\hline \multicolumn{17}{|l|}{ Age (years) } \\
\hline$\leq 39(\mathrm{n}=24)$ & 17 & 6 & 1 & 0 & 5 & 11 & 7 & 1 & 5 & 2 & 1 & 16 & 7 & 5 & 6 & 6 \\
\hline $40-49(n=46)$ & 28 & 11 & 7 & 0 & 9 & 18 & 12 & 7 & 9 & 5 & 2 & 30 & 14 & 9 & 11 & 12 \\
\hline $50-59(n=37)$ & 22 & 10 & 5 & 0 & 10 & 12 & 10 & 5 & 8 & 5 & 0 & 24 & 9 & 6 & 7 & 15 \\
\hline$\geq 60(n=21)$ & 15 & 5 & 1 & 0 & 4 & 9 & 5 & 3 & 4 & 1 & 3 & 13 & 5 & 2 & 4 & 10 \\
\hline \multicolumn{17}{|l|}{ Grade } \\
\hline $\mathrm{I}(\mathrm{n}=31)$ & 8 & 8 & 15 & 0 & 1 & 9 & 11 & 10 & 1 & 0 & 1 & 29 & 3 & 2 & 4 & 22 \\
\hline II $(n=61)$ & 41 & 21 & 0 & 0 & 9 & 25 & 21 & 6 & 14 & 9 & 4 & 34 & 16 & 18 & 12 & 15 \\
\hline III $(n=36)$ & 33 & 3 & 0 & 0 & 18 & 16 & 2 & 0 & 11 & 4 & 1 & 20 & 16 & 2 & 12 & 6 \\
\hline \multicolumn{17}{|l|}{ Positive nodes } \\
\hline $0(n=71)$ & 36 & 22 & 13 & 0 & 2 & 27 & 27 & 15 & 11 & 6 & 3 & 51 & 20 & 8 & 17 & 26 \\
\hline $1-3(n=23)$ & 15 & 7 & 1 & 0 & 6 & 14 & 3 & 0 & 7 & 3 & 2 & 11 & 1 & 9 & 4 & 9 \\
\hline$\geq 4(n=34)$ & 31 & 3 & 0 & 0 & 20 & 9 & 4 & 1 & 8 & 4 & 1 & 21 & 14 & 5 & 7 & 8 \\
\hline \multicolumn{17}{|l|}{ Tumor size $(\mathrm{cm})$} \\
\hline$<2.0(\mathrm{n}=56)$ & 36 & 11 & 9 & 0 & 11 & 20 & 15 & 10 & 10 & 4 & 3 & 39 & 15 & 12 & 12 & 17 \\
\hline $2.0-5.0(\mathrm{n}=62)$ & 39 & 19 & 4 & 0 & 14 & 25 & 18 & 5 & 13 & 5 & 1 & 43 & 18 & 9 & 14 & 21 \\
\hline$>5.0(\mathrm{n}=10)$ & 7 & 2 & 1 & 0 & 3 & 5 & 1 & 1 & 3 & 4 & 2 & 1 & 2 & 1 & 2 & 5 \\
\hline \multicolumn{17}{|l|}{ Stage } \\
\hline $\mathrm{I}(\mathrm{n}=34)$ & 22 & 9 & 3 & 0 & 2 & 14 & 8 & 10 & 7 & 3 & 2 & 22 & 11 & 3 & 8 & 12 \\
\hline II $(n=77)$ & 47 & 19 & 11 & 0 & 17 & 32 & 23 & 5 & 15 & 7 & 3 & 52 & 19 & 18 & 16 & 24 \\
\hline III $(n=17)$ & 13 & 4 & 0 & 0 & 9 & 4 & 3 & 1 & 4 & 3 & 1 & 9 & 5 & 1 & 4 & 7 \\
\hline
\end{tabular}

${ }^{a}$ Statistically significant p-value $<0.01$ in grade; ${ }^{b}$ statistically significant p-value $<0.05$ in positive nodes; ${ }^{\mathrm{c}}$ statistically significant $\mathrm{p}$-value $<0.01$ in positive nodes; ${ }^{\mathrm{d}}$ statistically significant $\mathrm{p}$-value $<0.01$ in stage; ${ }^{\mathrm{e}}$ statistically significant $\mathrm{p}$-value $<0.05$ in grade. 
Table II. Interrelation between the Pin-1 and cyclin D1 immunoexpression in mammary infiltrating duct carcinoma (\%).

\begin{tabular}{|c|c|c|c|c|c|}
\hline & \multicolumn{4}{|c|}{ Pin-1 } & \multirow[b]{2}{*}{ p-value } \\
\hline & $3+(n=82)$ & $2+(n=32)$ & $1+(\mathrm{n}=14)$ & $-(n=0)$ & \\
\hline \multicolumn{6}{|l|}{ Cyclin D1 } \\
\hline $3+(n=35)$ & 33 (94.3) & $2(5.7)$ & 0 & 0 & \multirow{3}{*}{$<0.05$} \\
\hline $2+(n=22)$ & $19(86.4)$ & $5(22.7)$ & $1(4.6)$ & 0 & \\
\hline $1+(n=28)$ & $16(57.1)$ & 8 (28.6) & $4(14.3)$ & 0 & \\
\hline$-(n=43)$ & $14(32.6)$ & $17(39.5)$ & $12(27.9)$ & 0 & \\
\hline
\end{tabular}

Table III. Multivariate analysis on disease-related survival (Cox proportional hazard model) according to the clinicopathological variables in mammary infiltrating duct carcinoma.

\begin{tabular}{lcc}
\hline Variable & Hazard ratio & 95\% confidence intervals \\
\hline Age & 0.991 & $0.961-1.023$ \\
Tumor grade & 1.223 & $0.727-2.057$ \\
Positive nodes & 2.041 & $1.260-3.305$ \\
Tumor size & 2.107 & $1.279-3.472$ \\
Stage & 0.689 & $0.308-1.542$ \\
\hline
\end{tabular}

$(\mathrm{p}<0.05)$, and it did not significantly correlate to the age of patient, the level of lymph node metastasis, tumor size or clinical disease stage. In other words, as tumor grade increased, strong increase of the expression of $\mathrm{p} 53$ protein was observed (Table I).

Correlation between cyclin D1 expression and clinicopathological parameters. The expression of cyclin D1 and histological grade as well as the level of lymph node metastasis correlated significantly ( $\mathrm{p}<0.05$ each), but it did not correlate to the age of patient, tumor size or clinical stage (Table I).

Correlation among the expression of Pin-1,VEGF-C, p53 protein and cyclin $D 1$. When Pin-1 was strongly positive, cyclin D1 was strongly positive in 33 cases, moderately positive in 19 cases, weak positive in 16 cases, and negative in 14 cases. In cases where Pin-1 was moderately positive, cyclin D1 was strongly positive in 2 cases, moderately positive in 5 cases, weakly positive in 8 cases, and negative in 17 cases. When Pin-1 was weakly positive, cyclin D1 was strongly positive in 0 case, moderately positive in 1 case, weakly positive in 4 cases, and negative in 12 cases. In such a manner, when Pin-1 was expressed strongly, the expression of cyclin D1 was elevated significantly $(\mathrm{p}<0.05)$. However, among the expression of Pin-1, VEGF-C, and p53, and among the expression of VEGF-C, p53, and cyclin D1, a statistical significance was not observed (Table II).

Correlation between the expression of Pin-1, VEGF-C, p53 protein or cyclin D1 and patient survival or survival length. Depending on the staining intensity of Pin-1, VEGF-C and p53 protein, survival rates and the survival length showed a slight difference. Positive expression, particularly in cases showing strong positivity, a trend for decrease of survival rates and the survival length was shown, nonetheless, it was not statistically significant. The rate of survival depending on the overexpression of cyclin D1 was statistically significant $(\mathrm{p}<0.05)$, and in cases without expressing cyclin $\mathrm{D} 1,76 \%$ cases survived during the follow- up period, and in cases exhibiting overexpression, $63 \%$ survived, which shows that the expression of cyclin D1 correlates significantly to survival rates. However, the degree of cyclin D1 expression and the survival length were not significantly different.

Correlation between clinicopathological parameters and survival length. The 5-year survival rate of the patients in the follow-up examination was $72 \%$. The correlation of the survival length, the age of patient, tumor size, tumor grade, the presence or absence of lymph node metastasis, the level of lymph node metastasis and clinical stage was examined, and it was found that tumor size as well as the presence or absence of lymph node metastasis mediated statistically significant effects on survival rates and the survival length, and induced the shortening of the survival length. However, the age of patient, tumor grade, the level of lymph node metastasis and clinical stage did not show a significant correlation to the survival length (Table III). In regard to the 5-year survival rate and the mean survival length according to age, the group younger than 39 years was $59 \%$ and 71 months, the 40-49 years group was $70 \%$ and 77 months, the $50-59$ years group was $83 \%$ and 87 months, the group older than 60 years was $57 \%$ and 74 months, and the survival rate and the survival length according to age was not statistically significant $(\mathrm{p}>0.05)$. Concerning the 5-year survival rate and the mean survival length, the grade I was $87 \%$ and 89 months, the grade II was $66 \%$ and 77 months, the grade III was $71 \%$ and 80 months, and the 5-year survival rate and the survival length according to histological grade were not statistically significant $(\mathrm{p}>0.05)$. Regarding the 5-year survival rate and the average survival period according to tumor size, the group with tumor size $<2 \mathrm{~cm}$ was $86 \%$ and 91 months, the $2-5 \mathrm{~cm}$ group was $74 \%$ and 84 months, the group $>5 \mathrm{~cm}$ was $32 \%$ and 49 months, and the 5-year survival rate and the survival length according to tumor size were statistically significant $(\mathrm{p}<0.05)$, and as tumor size becomes larger, the survival rate and the survival length were significantly decreased, and in cases with tumor size $>5 \mathrm{~cm}$, 


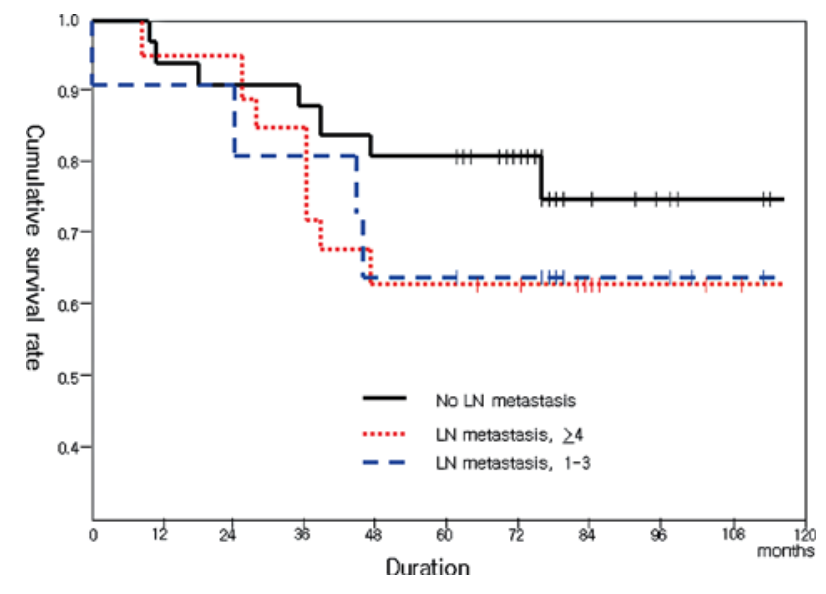

Figure 5. Cumulative survival curve by lymph node metastasis.

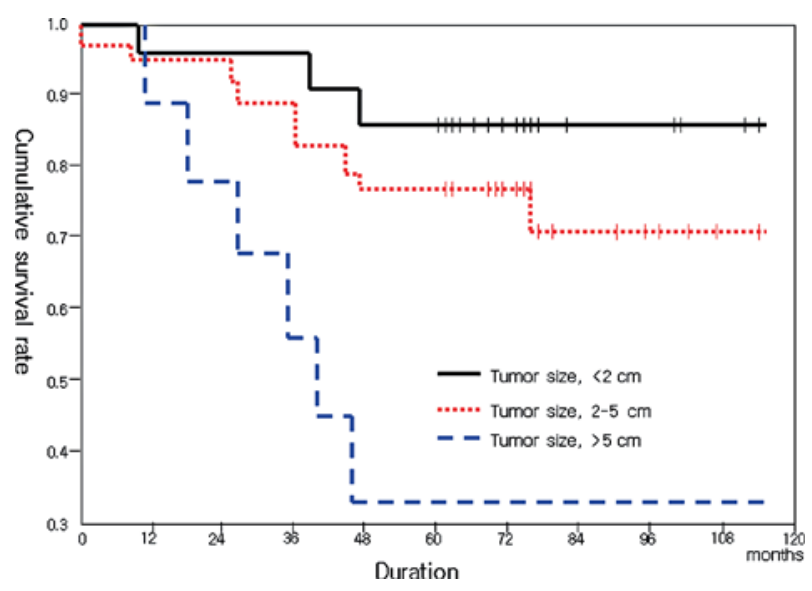

Figure 6. Cumulative survival curve by tumor size.

a noticeable difference was shown (Fig. 5), nevertheless, in the comparison depending on the number of metastatic lymph node, statistical significance was not detected ( $p>0.05$ ). However, according to the result of Cox regression model that is a multivariate analysis method of the age of patient, tumor size, tumor grade, the presence or absence of lymph node metastasis, the level of lymph node metastasis, clinical stage, and the survival length, only the presence or absence of lymph node metastasis was significant, and in comparison with the group absent lymph node metastasis, the group with metastasis in 1-3 nodes was 2.2 times, the group developed metastasis in $>4$ nodes was $\sim 6.2$ times, and the statistically significant increase of mortality was shown (confidence level, 1.16-33.17) (Fig. 6).

\section{Discussion}

Pin-1 has been known to control not only DNA replication checkpoints but also several cell cycle points such as $G_{1} / S$ and $G_{2} / M(1,5,6,26-28)$, its expression is noticeably increased in many cancers, and it has been reported to be involved in the stability of certain phosphoproteins $(1,5,6)$. Cells lacking Pin-1 develop serious defects in cell cycle checkpoints induced by DNA damages. In addition, DNA damage induces the stabilization and accumulation of p53 that plays a central role in the transcriptional activation of p21 and cell cycle arrest. DNA damage strengthens the interaction of Pin-1 and p53, which is determined by the WW domain of Pin-1 and the Ser/Pro motifs of p53. Furthermore, Pin-1 controls p53 stability and the transcriptional activation to $\mathrm{p} 21$ promoter, and thus in Pin-1 knock-out cells or Pin-1 defect tumor cells, even after DNA damage, the increase of p53 or p21 is hardly induced (29). The suppression of Pin-1 induces apoptosis, and the over-expression of Pin-1 increases cyclin D1 protein, and activates its promoter. Furthermore, Pin-1 binds to phosphorylated c-Jun with Ser67/73-Pro motifs induced by activated JNK or oncogenic Ras, Pin-1, in collaboration with activated Ras or JNK, augments transcriptional activity of c-Jun toward cyclin D1 promoter. Therefore, it is determined that the over-expression of Pin-1 in breast cancer augments cyclin D1 through the action of Ras and c-Jun and thus plays a central role in oncogenesis and tumor growth (6). In our study, the overexpression of Pin-1 was statistically significant with tumor grade as well as the level of lymph node metastasis. Nonetheless, it did not significantly correlate to tumor size or clinical stage. In addition, the correlation of Pin-1 and cyclin D1 was examined, and it was found that when Pin-1 was expressed strongly, the expression of cyclin D1 was also significantly increased.

On the other hand, even in normal breast tissues in the vicinity of tumors, weak staining of Pin-1 (1+) was detected in the nucleus, however, in infiltrating duct carcinoma cases, moderately or strongly positive expression $(2+$ or $3+)$ was observed in most cases, and thus the overexpression of Pin-1 was determined to be closely associated with tumors, and DCIS cases present in the vicinity of tumors was weakly positive (1+) in most cases, and thus it is speculated to play an important role in the tumor progression process rather than the neoplastic transformation stage.

The critical size that a mass could grow by the diffusion of oxygen and nutrition simply without angiogenesis is 1-2 mm in diameter, and it could not grow more than $3-5 \mathrm{~mm}^{3}$ $(30,31)$. Therefore, for tumors to grow further, to form new colonies in the vicinity, and to induce metastasis in lymph nodes or other tissues, new blood vessels should be formed within tumors as well as in the vicinity of tumors. The vascular wall of neovasculatures formed in such a manner is weaker than previous normal blood vessels, and thus cancer cells could infiltrate readily, and it also provides the passage for lymph node metastasis. In addition, for the growth of metastasized tumors, angiogenesis is a prerequisite. Therefore, numerous studies and attempts were made to precisely understand the mechanism of the angiogenesis of tumors, to predict prognosis based on this, and to apply the knowledge to treatments, nevertheless, it is not elucidated yet.

Several factors stimulating the formation of blood vessels are known, such as acidic fibroblast growth factor (aFGF), basic fibroblast growth factor (bFGF), transforming growth factor- $\beta$ (TGF- $\beta$ ), VEGF, platelet derived endothelial cell growth factor (PD-ECGF), interleukin-8, hepatocyte growth factor, and proliferin (32-35), and among them, VEGF is a substance inducing strong mitosis by acting on vascular 
endothelial cells selectively, and it has been reported to be the most important and potent factor for the angiogenesis of tumors. Endothelial cell growth factors with the structural homology to VEGF have been continuously characterized, and VEGF-C belonging to the VEGF family is a ligand of VEGF receptor-3 (VEGFR-3, Flt-4), it is known to be a specific marker of lymphatic duct endothelial cells, and to induce proliferation of lymphatic ducts $(9,10)$. VEGF-C has been reported not only to control physiological angiogenesis, the development and progression of various angiogenetic diseases but also to stimulate tumor lymphangiogenesis and thus to induce the dissemination of various tumor cells and lymph node metastasis $(11,12)$. In cases with transitional cell carcinoma in the bladder, the expression of VEGF-C has been revealed to be a useful factor allowing to predict lymph node metastasis as well as poor prognosis (36), and in breast cancer, the strong expression of VEGF-C or COX-2 induces statistically significant recurrence rate and mortality, and the simultaneous expression of VEGF-C and COX-2 is associated with lymphangiogenesis, determining that COX-2 stimulates lymph node metastasis through the lymphangiogenesis pathway by augmenting the expression of VEGF-C (8). In addition, it has been shown that COX-2 was significantly associated with the expression of VEGF or cyclin D1, it exerts significant effects on tumor grade, lymph node metastasis and tumor size, and significant coexpression of COX-2 and VEGF was shown (37). It has been revealed that in glioblastoma, VEGF secretion was accelerated by tumor cells under hypoxic condition and thus induced the proliferation of new blood vessels (38), and subsequently, it has been also revealed in experiments that in tumor cell culture, VEGF plays an important role in the proliferation of vascular endothelial cells (39). The expression of VEGF is elevated primarily by the decrease of oxygen partial pressure, and in addition, its expression is controlled by cytokines such as EGF, TGF- $\beta$, keratinocyte growth factor, and $p 53$ and other tumor suppressor genes (40-42). However, studies examined their effect on VEGF-C are still rare.

In our study, the expression of VEGF-C was statistically significantly associated with tumor grade, lymph node metastasis, and clinical stage, nevertheless, it did not significantly correlate to the expression of Pin-1, p53 protein and cyclin D1. In addition, concerning the expression of VEGF-C, depending on the staining intensity, mortality and the survival length showed slight differences. In positive expression, particularly in cases showing strong positive expression, a tendency for decreased mortality and the survival length was shown, however, it was not statistically significant.

The tumor suppressor gene $p 53$ is present within the nucleus in cells and involved in the control of cell cycle, and when stress is delivered to cells or DNA damage is caused, it repairs DNA while arresting cell cycle at G1 stage, and it plays a role of suppressing cell proliferation and transformation by activating several other tumor suppressor genes. However, when this gene is mutated, cell cycle enters the $S$ phase before the repair of damaged DNA, induces the rearrangement of chromosomes or the amplification of genes resulting in the formation of tumors $(43,44)$. p53 gene is the most frequent target of genetic mutation occurring in diverse cancers $(45,46)$. It has been shown that the accumulation of mutant p53 protein occurs in diverse malignant tumors developing in the breast, lung, and digestive tract (20,47-49). In breast cancer cases, the accumulation of mutant p53 protein is observed in $10-40 \%$, and it has been revealed to be increased in estrogen receptor-negative cases, epithelial growth factor receptor-positive cases, and in higher nuclear grade of tumors, and thus it is considered to be of help in the determination of biological characteristics of tumors as well as the prognosis of patient $(20,44)$.

In our study, the expression of p53 protein was observed in $35 \%$, and as the tumor grade became higher, its expression was increased, and thus it is thought to be associated with poor prognosis, however, it did not significantly correlate to the survival rate of patients. According to previous studies, it correlated significantly to tumor grade, however, it did not correlate significantly to lymph node metastasis, and thus it was inferred that it might not be an independent prognostic factor, on the other hand, contradictory results that the presence or absence of lymph node metastasis correlated to the expression of $\mathrm{p} 53$ protein or the survival length of patient have been reported $(20,50,51)$.

In the control of the cell cycle, a series of activation and inactivation processes due to the balance of the cyclin-cyclin dependent kinase (cdk) complex and cdk suppression protein is very important for the formation of tumors, and among the cell cycle progression processes, the G1/S transition stage is the most important. The essential complex of this stage is cyclin D1-cdk4 $(52,53)$. Cyclin D1 is located in chromosome 11q13, and the overexpression by the rearrangement as well as amplification of this gene has been observed in several tumor types. Among the cyclin series, cyclin D1 that has been reported to be related most to the formation of tumor is expressed primarily in the G1 phase, it suppresses the function of retinoblastoma $(\mathrm{Rb})$ protein or other tumor suppressor genes by $\mathrm{Rb}$ protein and it could induce the transformation of cells (54). Cyclin D1 plays a central role in the development of various cancers, particularly breast cancer, and the overexpression of cyclin D1 induces the transformation of cells, however, the suppression of cyclin D1 expression causes the growth arrest of tumor cells $(55,56)$. Furthermore, in murine mammary gland, the transgenic overexpression of cyclin D1 induces mammary hyperplasia and ultimately carcinoma (57). More importantly, in mice, when cyclin Dl gene was destroyed, the ability of Ha-ras or c-Neu/HER2 inducing the development of tumors in the mammary gland was completely suppressed (58). Such results suggest that cyclin D1 is an essential downstream target in the process of the formation of breast cancer induced by Ha-ras or c-Neu, and the major mechanism of the tumor formation process is the phosphorylation process of pSer/Thr-Pro motifs. In protein, pSer/Thr-Pro motifs are present as two types of completely different cis and trans structure, and their conversion is induced by the catalytic action of prolyl isomerase Pin-1 $(2,26,59,60)$. After the induction of phoshorylation, the conformational change of protein caused by Pin-1 mediates a great influence on their catalytic activity, dephosphorylation, and protein-protein interaction $(1,3,4,61)$. Therefore, phosphorylation-dependent prolyl isomerization is the 
decisive control mechanism of the phosphorylation signal transduction system (27).

In our study also, when Pin-1 was expressed strongly, the expression of cyclin D1 was increased significantly, concurring well with previous research.

The expression of cyclin D1 showed different results depending on organs and investigators, and in soft tissue sarcoma cases, the overexpression was associated with poor prognosis (62), in breast cancer cases, it has been reported to be associated with good prognosis $(63,64)$ and it did not correlate contrarily $(65,66)$, and in head and neck squamous cell carcinoma, it has been reported to be associated with poor prognosis (67). In 10-20\% of breast cancer, the amplification of cyclin D1 gene was detected, nevertheless, the overexpression of cyclin D1 protein was shown to be approximately $35-80 \%$, and thus it varies widely depending on investigators (68-70). The overexpression of cyclin D1 protein was higher than the frequency of gene amplification, which implies that the expression of cyclin D1 protein could be induced by mechanisms other than gene amplification, it may be induced by mutation or translocation, and it may be due to the enhancement of the sensitivity to hormone, particularly, estrogen (65). In experiments using a breast cancer cell line, cyclin D1 could be induced by estrogen, and thus even without the amplification of the gene, the expression of cyclin D1 could be induced in estrogen receptor-positive cells (71), and in estrogen receptor-positive cells, more cyclin D1 could be synthesized (72).

In our cases, the overexpression of cyclin D1 was observed in 85 cases $(66 \%)$ and a significant correlation of the expression of cyclin D1 and the expression of Pin-1 was detected, however, it did not significantly correlate to the expression of VEGF-C and p53. In addition, the correlation of cyclin D1 to various clinicopathological markers was examined, and it did not correlate to patient age, tumor size, clinical stage, however, the expression intensity of cyclin D1 significantly correlated to the presence or absence of lymph node metastasis as well as tumor grade. In regard to the rate of survival and the survival length according to the nonexpression of cyclin D1 and its overexpression, in cases with the overexpression of cyclin D1, the survival rate as well as the survival length was statistically significantly increased, however, the survival length according to the degree of cyclin D1 overexpression was not significant, and thus it is determined that whether cyclin D1 is expressed or not may be valuable as a predictive factor mediating effects on the survival rate and the survival length.

In addition, the relationship of various clinicopathological markers with the survival length was statistically analyzed, and tumor size as well as the presence or absence of metastasis mediated statistically significant effects on the survival rate as well as the survival length, and thus induce the shortening of the survival length. However, the age of patient, tumor grade, the degree of lymph node metastasis, and clinical stage did not correlate significantly to the survival rate or the survival length.

Based on these findings, Pin-1 and VEGF-C were confirmed to be involved in the progression of breast cancer as well as metastasis, they induce poor prognosis, and as shown previously, p53 protein and cyclin D1 also were confirmed to be negative prognostic factors. In addition, although more studies on Pin-1 as well as VEGF-C should be accumulated, the expression of Pin-1 and cyclin D1 was closely associated, and the expression of VEGF-C and tumor grade, the level of lymph node metastasis and clinical stage were statistically significant, and thus it is determined that it could be used widely as basic information to establish a strategy for chemotherapy.

\section{Acknowledgements}

This study was supported by the KOSEF grant funded by the Korea government (MEST) through the Research Center for Resistant Cells (R13-2003-009) and research funds from Chosun University, 2007.

\section{References}

1. Liou YC, Ryo A, Huang HK, Lu PJ, Bronson R, Fujimori F, Uchida T, Hunter T and Lu KP: Loss of Pin1 function in the mouse causes phenotypes resembling cyclin D1-null phenotypes. Proc Natl Acad Sci USA 99: 1335-1340, 2002.

2. Lu PJ, Wulf G, Zhou XZ, Davies P and Lu KP: The prolyl isomerase Pin 1 restores the function of Alzheimer-associated phosphorylated tau protein. Nature 399: 784-788, 1999.

3. Lu PJ, Zhou XZ, Shen M and Lu KP: Function of WW domains as phosphoserine- or phosphothreonine-binding modules. Science 283: 1325-1328, 1999.

4. Ryo A, Liou YC, Wulf G, Nakamura M, Lee SW and Lu KP: PIN1 is an E2F target gene essential for Neu/Ras-induced transformation of mammary epithelial cells. Mol Cell Biol 22: 5281-5295, 2002.

5. Ryo A, Nakamura M, Wulf G, Liou YC and Lu KP: Pin1 regulates turnover and subcellular localization of beta-catenin by inhibiting its interaction with APC. Nat Cell Biol 3: 793-801, 2001.

6. Wulf GM, Ryo A, Wulf GG, Lee SW, Niu T, Petkova V and Lu KP: Pin 1 is overexpressed in breast cancer and cooperates with Ras signaling in increasing the transcriptional activity of c-Jun towards cyclin D1. EMBO J 20: 3459-3472, 2001.

7. Stacker SA, Hughes RA and Achen MG: Molecular targeting of lymphatics for therapy. Curr Pharm Des 10: 65-74, 2004.

8. Zhang XH, Huang DP, Guo GL, Chen GR, Zhang HX, Wan L and Chen SY: Coexpression of VEGF-C and COX-2 and its association with lymphangiogenesis in human breast cancer. BMC Cancer 8: 4, 2008.

9. Joukov V, Pajusola K, Kaipainen A, Chilov D, Lahtinen I, Kukk E, Saksela O, Kalkkinen N and Alitalo K: A novel vascular endothelial growth factor, VEGF-C, is a ligand for the Flt4 (VEGFR-3) and KDR (VEGFR-2) receptor tyrosine kinases. EMBO J 15: 290-298, 1996.

10. Jeltsch M, Kaipainen A, Joukov V, Meng X, Lakso M, Rauvala H, Swartz M, Fukumura D, Jain RK and Alitalo K: Hyperplasia of lymphatic vessels in VEGF-C transgenic mice. Science 276 : 1423-1425, 1997.

11. Cao Y, Linden P, Farnebo J, Cao R, Eriksson A, Kumar V, Qi JH, Claesson-Welsh L and Alitalo K: Vascular endothelial growth factor C induces angiogenesis in vivo. Proc Natl Acad Sci USA 95: 14389-14394, 1998

12. Mandriota SJ, Jussila L, Jeltsch M, Compagni A, Baetens D, Prevo R, Banerji S, Huarte J, Montesano R, Jackson DG, Orci L, Alitalo K, Christofori G and Pepper MS: Vascular endothelial growth factor-C-mediated lymphangiogenesis promotes tumour metastasis. EMBO J 20: 672-682, 2001.

13. National Cancer Information Center. Ministry for Health, Welfare and Family Affairs, National Cancer Center. Cancer Statistics, 2008, www.cancer.go.kr

14. Page DL: Prognosis and breast cancer: recognition of lethal and favorable prognostic types. Am J Surg Pathol 15: 334-349, 1991.

15. Fisher ER: The impact of pathology on the biologic, diagnostic, prognostic and therapeutic considerations in breast cancer. Surg Clin North Am 64: 1073-1093, 1984.

16. Clark GM, Dressler LG, Owens MA, Pounds G, Oldaker T and McGuire WL: Prediction of relapse or survival in patients with node-negative breast cancer by DNA flow cytometry. N Eng J Med 320: 627-633, 1989. 
17. Henderson BE, Ross RK, Pike MC and Casagrande JT: Endogenous hormones as a major factor in human cancer. Cancer Res 42: 3232-3239, 1982 .

18. Parl FF, Schmidt BP, Dupont WD and Wagner RK: Prognostic significance of estrogen receptor status in breast cancer in relation to tumor stage, axillary node metastasis and histopathologic grading. Cancer 54: 2237-2242, 1984

19. Slamon DJ, Clark GM, Wong SG, Levin WJ, Ullrich A and McGuire WL: Human breast cancer: correlation of relapse and survival with amplification of the HER-2/neu oncogene. Science 235: $177-182,1987$

20. Cattoretti G, Rilke F, Andreola S, D'Amato L and Delia D: p53 expression in breast cancer. Int J Cancer 41: 178-183, 1988

21. Elston CW and Ellis IO: Pathological prognostic factors in breast cancer. I. The value of histological grade in breast cancer: experience from a large study with long-term followup. Histopathology 19: 403-410, 1991.

22. Greene FL, Page DL and Fleming ID (eds): AJCC Cancer Staging Manual. 6th edition. Springer-Verlag, NewYork, 2002.

23. Fisher ER, Sass R and Fisher B: Pathologic findings from the national surgical adjuvant project for breast cancers (protocol No. 4). X. Discriminants for tenth year treatment failure. Cancer 53: 712-723, 1984.

24. Nakashima M, Meirmanov S, Naruke Y, Kondo H, Saenko V, Rogounovitch T, Shimizu-Yoshida Y, Takamura N, Namba H, Ito M, Abrosimov A, Lushnikov E, Roumiantsev P, Tsyb A Yamashita S and Sekine I: Cyclin D1 overexpression in thyroid tumours from a radio-contaminated area and its correlation with Pin 1 and aberrant beta-catenin expression. J Pathol 202: 446 $455,2004$.

25. Lim SC and Lee MS: Significance of E-cadherin/beta-catenin complex and cyclin D1 in breast cancer. Oncol Rep 9: 915-928, 2002.

26. Lu KP, Hanes SD and Hunter T: A human peptidyl-prolyl isomerase essential for regulation of mitosis. Nature 380: 544-547, 1996

27. Lu KP, Liou YC and Zhou XZ: Pinning down proline-directed phosphorylation signaling. Trends Cell Biol 12: 164-172, 2002 .

28. Winkler KE, Swenson KI, Kornbluth S and Means AR Requirement of the prolyl isomerase Pin 1 for the replication checkpoint. Science 287: 1644-1647, 2000.

29. Wulf GM, Liou YC, Ryo A, Lee SW and Lu KP: Role of Pin in the regulation of p53 stability and p21 transactivation, and cell cycle checkpoints in response to DNA damage. J Biol Chem 277: 47976-47979, 2002.

30. Folkman J: How is blood vessel growth regulated in normal and neoplastic tissue. Cancer Res 46: 467-473, 1986.

31. Zatterstrom UK, Brun E, Willen R, Kjellen E and Wennerberg J: Tumor angiogenesis and prognosis in squamous cell carcinoma of the head and neck. Head Neck 17: 312-318, 1995

32. Keck PJ, Hauser SD, Krivi G, Sanzo K, Warren T, Feder J and Connolly DT: Vascular permeability factor, an endothelial cell mitogen related to PDGF. Science 246: 1309-1312, 1989.

33. Senger DR, Galli SJ, Dvorak AM, Perruzzi CA, Harvey VS and Dvorak HF: Tumor cells secrete a vascular permeability factor that promotes accumulation of ascitic fluid. Science 219: 983-985, 1983 .

34. Folkman J and Shing Y: Angiogenesis. J Biol Chem 267: 10931-10934, 1992

35. Dvorak HF, Orenstein NS, Carvalho AC, Churchill WH, Dvorak AM, Galli SJ, Feder J, Bitzer AM, Rypysc J and Giovinco P: Induction of a fibrin-gel investment: an early event in line 10 hepatocarcinoma growth mediated by tumor secreted by products. J Immunol 122: 166-174, 1979

36. Suzuki K, Morita T and Tokue A: Vascular endothelial growth factor-C (VEGF-C) expression predicts lymph node metastasis of transitional cell carcinoma of the bladder. Int J Urol 12 : $152-158,2005$

37. Lim SC: Role of COX-2, VEGF and cyclin D1 in mammary infiltrating duct carcinoma. Oncol Rep 10: 1241-1249, 2003.

38. Horak E, Leek R, Klenk N, Lejeune S, Smith K and Stuart N: Angiogenesis assessed by platelet endothelial cell adhesion molecule antibodies, as an indicator of node metastasis and survival in breast cancer. Lancet 340: 1120-1124, 1992.

39. Viglietto G, Maglione D, Rambaldi M, Cerutti J, Romano A and Trapasso F: Upregulation of vascular endothelial growth factor and down regulation of placenta growth factor associated with malignancy in human thyroid tumors and cell lines. Oncogene 11: 1569-1579, 1995 .
40. Frank S, Hubner G, Breier G, Longaker MT, Greenhalgh DG and Werner S: Regulation of vascular endothelial growth factor expression in cultured keratinocytes. Implication for normal and impaired wound healing. J Biol Chem 270: 12607-12613, 1995.

41. Dameron KM, Volpert OV, Tainsky MA and Bouck N: Contro of angiogenesis in fibroblasts by p53 regulation of thrombospondin-1. Science 265: 1582-1584, 1994.

42. Kieser A, Weich HA, Brandner G, Marme D and Kolch W: Mutant p53 potentiates protein kinase $\mathrm{C}$ induction of vascular endothelial growth factor expression. Oncogene 9: 963-969, 1994.

43. Dergham ST, Dugan MC, Joshi US, Chen YC, Du W, Smith DW, Arlauskas P, Crissman JD, Vaitkevicius VK and Sarkar FH: The clinical significance of p21(WAF1/CIP-1) and p53 expression in pancreatic adenocarcinoma. Cancer 80: 372-381, 1997.

44. Bukholm IK, Nesland JM, Karesen R, Jacobsen U and Børresen AL: Relationship between abnormal p53 protein and failure to express p21 protein in human breast carcinomas. J Pathol 181: 140-145 1997.

45. Zambetti GP and Levine AJ: A comparison of the biological activities of wild-type and mutant p53. FASEB J 7: 855-865, 1993.

46. Chang F, Syrjänen S, Kurvinen K and Syrjänen K: The p53 tumor suppressor gene as a common cellular target in human carcinogenesis. Am J Gastroenterol 88: 174-186, 1993.

47. Rodrigues NR, Rowan A, Smith ME, Kerr IB, Bodmer WF, Gannon JV and Lane DP: p53 mutations in colorectal cancer. Proc Natl Acad Sci USA 87: 7555-7559, 1990.

48. Iggo R, Gatter K, Bartek J, Lane D and Harris AL: Increased expression of mutant forms of p53 oncogene in primary lung cancer. Lancet Mar 335: 675-679, 1990.

49. Bártek J, Bártková J, Vojtesek B, Stasková Z, Lukás J, Rejthar A Kovarík J, Midgley CA, Gannon JV and Lane DP: Aberrant expression of the p53 oncoprotein is a common feature of a wide spectrum of human malignancies. Oncogene 6: 1699-1703, 1991

50. Gao RJ, Bao HZ, Yang Q, Cong Q, Song JN and Wang L: The presence of serum anti-p53 antibodies from patients with invasive ductal carcinoma of breast: correlation to other clinical and biological parameters. Breast Cancer Res Treat 93: 111-115, 2005.

51. Rahko E, Blanco G, Soini Y, Bloigu R and Jukkola A: A mutant TP53 gene status is associated with a poor prognosis and anthracycline-resistance in breast cancer patients. Eur J Cancer 39: 447-453, 2003.

52. Weinberg RA: The retinoblastoma protein and cell cycle control Cell 81: 323-330, 1995

53. Cordon-Cardo C: Mutation of cell cycle regulators. Biological and clinical implications for human neoplasia. Am J Pathol 147: 545-560, 1995 .

54. Dowdy SF, Hinds PW, Louie K, Reed SI, Arnold A and Weinberg RA: Physical interaction of the retinoblastoma protein with human D cyclins. Cell 73: 499-511, 1993.

55. Alt JR, Cleveland JL, Hannink M and Diehl JA: Phosphorylation-dependent regulation of cyclin D1 nuclear export and cyclin D1-dependent cellular transformation. Genes Dev 14: 3102-3114, 2000 .

56. Hinds PW, Dowdy SF, Eaton EN, Arnold A and Weinberg RA: Function of a human cyclin gene as an oncogene. Proc Natl Acad Sci USA 91: 709-713, 1994

57. Wang TC, Cardiff RD, Zukerberg L, Lees E, Arnold A and Schmidt EV: Mammary hyperplasia and carcinoma in MMTVcyclin D1 transgenic mice. Nature 369: 669-671, 1994.

58. Yu Q, Geng Y and Sicinski P: Specific protection against breast cancers by cyclin D1 ablation. Nature 411: 1017-1021, 2001.

59. Ranganathan R, Lu KP, Hunter T and Noel JP: Structural and functional analysis of the mitotic rotamase Pin 1 suggests substrate recognition is phosphorylation dependent. Cell 89 : 875-886, 1997

60. Zhou XZ, Lu PJ, Wulf G and Lu KP: Phosphorylation-dependent prolyl isomerization: a novel signaling regulatory mechanism. Cell Mol Life Sci 56: 788-806, 1999.

61. Hsu T, McRackan D, Vincent TS and Gert de Couet H: Drosophila Pin1 prolyl isomerase Dodo is a MAP kinase signal responder during oogenesis. Nat Cell Biol 3: 538-543, 2001.

62. Kim SH, Lewis JJ, Brennan MF, Woodruff JM, Dudas M and Cordon-Cardo C: Overexpression of cyclin D1 is associated with poor prognosis in extremity soft tissue sarcomas. Clin Cancer Res 4: 2377-2382, 1998. 
63. Gillett C, Fantl V, Smith R, Fisher C, Bartek J, Dickson C, Barnes D and Peters G: Amplification and overexpression of cyclin D1 in breast cancer detected by immunohistochemical staining. Cancer Res 54: 1812-1817, 1994.

64. Bates S, Parry D, Bonetta L, Vousden K, Dickson C and Peters G: Absence of cyclin D/cdk complexes in cells lacking functional retinoblastoma protein. Oncogene 9: 1633-1640, 1994.

65. Van Diest PJ, Michalides RJ, Jannink L, van der Valk P, Peterse HL, Meijer CJ and Baak JP: Cyclin D1 expression in invasive breast cancer. Correlations and prognostic value. Am J Pathol 150: 705-711, 1997.

66. Michalides R, Hageman P, van Tinteren H, Houben L, Wientjens E and Peterse J: A clinicopathologic study on overexpression of cyclin D1 and p53 in a series of 248 patients with operable breast cancer. Br J Cancer 73: 728-734, 1996.

67. Akervall JA, Michalides RJ, Mineta H, Balm A, Borg A, Dictor MR, Jin Y, Loftus B, Mertens F and Wennerberg JP: Amplification of cyclin D1 in squamous cell carcinoma of the head and neck and the prognostic value of chromosomal abnormalities and cyclin D1 overexpression. Cancer 79: 380-390, 1997.
68. Bartkova J, Lukas J, Muller H, Lutzhoft D, Strauss M and Bartek J: Cyclin D1 expression and function in human breast cancer. Int J Cancer 57: 353-361, 1994.

69. Zhang SY, Caamano J, Cooper F, Guo X and Klein-Szanto AJ: Immunohistochemistry of cyclin D1 in human breast cancer. Am J Clin Pathol 102: 695-698, 1994

70. Zukerberg LR, Yang WI, Gadd M, Thor AD, Koerner FC, Schmidt EV and Arnold A: Cyclin D1(PRAD1) protein expression in breast cancer: approximately one-third of infiltrating mammary carcinomas show overexpression of the cyclin D1 oncogene. Mod Pathol 8: 560-567, 1995.

71. Musgrove EA, Hamilton JA, Lee CS, Sweeney KJ, Watts CK and Sutherland RL: Growth factor steroid and steroid antagonist regulation of cyclin gene expression associated with changes in T47D human breast cancer cell cycle progression. Mol Cell Biol 13: 3577-3587, 1993.

72. Kim DH, Nam ES, Shin HS, Ryu JW, Go JH, Oh YL, Song SY Kim DS and Lee MC: Cyclin D1 expression in 101 cases of breast carcinoma. Korean J Pathol 32: 266-272, 1998. 